\title{
“UNESCO Policy of Education for all': Advancing access to inclusive education practice in special education in Imo State, Nigeria"
}

\author{
Umeh Ngozi Chuma*, Nnadi Ine**, \& Osuji Emma*** \\ Imo State University, Owerri, Nigeria
}

\begin{abstract}
This study investigates barriers to inclusive education practices as it affects children with disabilities in Imo state based on ideas of the social model of disability. Specifically, the study explores the fundamentals of successful implementation of inclusive education. Two research questions have been formulated. Identified government owned special basic schools within the 3 senatorial zones in Imo state is selected for the study. The zones include, Owerri, Orlu and Okigwe. The study participants generally, include children with disabilities, teachers, inclusive education consultants and policy makersinvolving particularly officials of the Imo State Universal Basic Education Boards- IMSUBEB in the sampled state. Descriptive and qualitative survey will be used for the study. Questionnaire, interviews and focus group discussions will be used to gather data.
\end{abstract}

\section{INTRODUCTION}

$I^{2}$ nclusive education seeks to put an end to exclusionary practices that both directly and indirectly exclude some children from accessing an appropriate education and is therefore an important approach for the realisation of the future and broader Agenda 2030 Sustainable Development Goal 4 adopted by nations in 2015. Indeed, one of the agenda 17 Sustainable Development Goals agreed by world leaders under the United Nations Sustainable development goals (2015) was to 'commit to providing inclusive and equitable quality education at all levels for all people, including persons with disabilities'. This goal is not likely to be achieved without appropriate commitment. According to UNESCO, over 30000000 million children of primary school age are out of school in Sub Saharan Africa (which includes Nigeria). Nigeria is stated to have the world's largest number of out of school children between 2004 and 2013. ${ }^{1}$ Research also shows that Nigeria still has about 12000200 out of school children and ascertaining the current percentage of those with learning

*LLB, LLM (Nigeria), LLD (Pretoria), Barrister-at-Law (Nigerian Law School), Senior Lecturer, Faculty of Law, Imo State University Owerri, Nigeria. umehngozi@gmail.com.

**LLB, LLM, Ph.D, Barrister-at-Law, Professor, Faculty of Law, Imo State University Owerri, Nigeria.

*** LLB, LLM, Ph.D Lecturer, Faculty of Law, Imo State University Owerri, Nigeria.

1 UNICEF Nigeria (2013) https://www.unicef.org/nigeria/education (accessed February 13 2019). disabilities is almost impracticable as no official data really exists in Nigeria. ${ }^{2}$

However, World Bank reports that 3 in 10 children with disabilities in Nigeria (including in Imo state) have never enrolled in school and educational plans do not address the needs of children with disabilities, thereby pushing them further away from full participation in the society. ${ }^{3}$ Also, the National President of Joint National Association of Persons with Disabilities (JONAPWD) stated that about 7000000 children with disabilities in Nigeria, including Imo state do not have access to quality education. ${ }^{4}$ This data is worrisome and calls for concern.

The Convention on the Rights of Persons with Disabilities (CRPD) provides for the right to inclusive education and heralded new thinking as to what it means to have a disability. Nigeria's ratification and domestication of the CRPD ${ }^{5}$ signifies the intention by states in Nigeria to give effect to its international documents and principles it has ratified in relation to state obligation under international law. The CRPD states that 'Persons with disabilities include those who have long-term physical, mental, intellectual or sensory impairments which in interaction with various barriers may hinder their full and effective participation in society on an equal basis with others'. ${ }^{6}$ This means that improvements in the life and education of persons with disabilities have to go beyond emphasising their impediments which have been the dominant focus of special education in Nigeria, to socio-

\footnotetext{
${ }^{2}$ UNESCO 'The Hidden Crisis: Armed conflict and education' Education for ALL Global Monitoring Report (2011) 3;

${ }^{3}$ World Bank Group (2018) 'A shortage of education opportunities for children with disabilities in Nigeria' available at https://www.globalpartnership.org/news-and-media/news/shortage-educationopportunities-children-disabilities-nigeria (accessed February 13 2019).

${ }^{4}$ Ekaete Umoh National President of the Joint National Association of Persons with Disabilities (JONAPWD) stated this at the media launch of the Baseline Survey conducted in Akwa-ibom, Kwara states and the Federal Capital Territory as part of an ongoing project on Advocacy for inclusive education and Accessible Universal Basic Education for Children with Disabilities in Nigeria and supported by USAID Strengthening Advocacy and Civic Engagement (SACE) Programme in Nigeria available at https://www.vanguardngr.com/2016/05/7m-children-disabilities-demandreview-education-policies/ accessed February 13 2019).

${ }^{5}$ Signed and ratified by Nigeria on 30 March 2007 and 24 September 2010 respectively

${ }^{6}$ See sec 1 of the CRPD
} 
political aspects involving how they are taught and the provision of needed facilities. Inclusive education has also been explained to mean a general education reform in all formal and informal educational settings in order to lessen the effect of actual or possible segregation in different and pervasive forms. $^{7}$

Given this global context, inclusive education has also received domestic endorsement in the Discrimination against Persons with Disabilities (Prohibition) Act because it is seen as ensuring education in least restrictive environment for persons with disabilities. ${ }^{8}$ Nigeria's National Policy on Education also aims towards the provision of equal educational opportunity, inclusive education and designing of appropriate diversified curriculum for all learners with disabilities. $^{9}$ It further stipulates that teachers should be trained and retrained for effective implementation of inclusive education. ${ }^{10}$

\section{STATEMENT OF THE PROBLEM/JUSTIFICATION}

Nigeria has enacted legislation and formulated policies that could make inclusive education work in the various states of the federation, including Imo state. However, these efforts have not been backed up with positive actions towards implementation. This statement is supported by reports that have been released by Disability Organisations in Nigeria, research, World Bank and Global Partners on Education on the lack of access to quality education to children with disabilities in Nigeria. ${ }^{11}$ In 2016, it was stated that about 7000 000 children with disabilities remain out of school because virtually all primary and secondary schools in Nigeria (which includes Imo State) were designed, built and managed in ways that are exclusionary and inaccessible. ${ }^{12}$ It has also been

\footnotetext{
${ }^{7}$ See the articulations in General Comment No 4 on inclusive education, adopted by the UN Committee on the Rights of Persons with Disabilities 2 September 2016, CRPD/C/GC/4- General Comment No 4 is an interpretation of the CRPD in terms of normative obligations towards learners with disabilities; see also R Slee 'Beyond special and regular schooling? An inclusive education reform agenda' (2008) 18 International Studies in Sociology of Education 99; D Armstrong 'Reinventing inclusion: New labour and the cultural politics of special education' (2005) 31 Oxford Review of Education 135; K Runswick-cole 'Time to end the bias towards inclusive education' (2011) 38 British Journal of Special Education 112.

8 The Discrimination Against Persons with Disabilities (Prohibition) Act, 2018, art 18.

${ }^{9}$ Nigeria National Policy on Education, 6th edition, 2013 para 119.

${ }^{10}$ Nigeria National Policy on Education, para 123.

${ }^{11}$ Further details at: Unpublished: NC Umeh, 'Realising access to inclusive education for hearing-impaired learners in Nigerian primary schools' unpublished: unpublished LLD thesis, University of Pretoria, South Africa, 2017; Daily Trust Newspaper (2017) 'Nigeria: Three million children with disability out of school available at https://allafrica.com/stories/201607140976.html (accessed February 13 2019); Global Partnership for Education -World Bank Group (2018) 'A shortage of education opportunities for children with disabilities in Nigeria' available at https://www.globalpartnership.org/news-and-media/news/shortage-educationopportunities-children-disabilities-nigeria (accessed February 13 2019); Ekaete Umoh National President of the Joint National Association of Persons with Disabilities (JONAPWD) available at https://www.vanguardngr.com/2016/05/7m-children-disabilities-demandreview-education-policies/ (accessed February 13 2019).

${ }^{12}$ See Ekaete Umoh (n 2 above).
}

estimated that more than 3000000 children with disabilities do not get quality education because school environments are not inclusive. ${ }^{13}$ Part of the reason for these high estimates of children with disabilities that are out of school in Nigeria, including in Imo state, is attributable to the barriers they encounter in accessing education services within and outside the school environment. Consequently, the study seeks to explore barriers that stultify the advancement of inclusive education practices for children with disabilities in Imo State.

\section{OBJECTIVES OF THE STUDY}

Aim: The main aim of this study is to explore:

How inclusive education principles can be actualised in basic education for children with disabilities in Imo state

Specific Objectives arising from the research question:

i. To determine research participants knowledge about main prerequisites of inclusive education under normative law.

ii. To determine the sufficiency of approaches adopted in the education of children with disabilities in Imo state special schools.

\section{METHODOLOGY}

The approach adopted in conducting this research generally is of descriptive and qualitative nature. Descriptive survey, scheduled interview and focus group discussions have been used to gather data for research questions 1 and 2. The combination of data sources was for purposes of logical triangulation in order to make for validity as learned. ${ }^{14}$

Population size, sampling techniques and quality of data

Four Imo state basic special schools within the three zones have been selected for questionnaire distribution, 2 from Owerri, I from okigwe and 1 from Orlu, and they have a population of 42 teachers and a population of 312 learners. Officials of States Universal Basic Education Board - SUBEB expected to respond to the survey questionnaire are 26 and 16 focus group discussants.

In order to obtain the sample size which will enable us draw inferences about the population size for questionnaire distribution in schools, the study engaged the services of a statistician to provide guidance in this regard.

A questionnaire titled; Key Ideas Supporting Inclusive Education Questionnaire (KISIEQ) has been administered in this study. Section A of this instrument covers the demographic data of the participants. Subsequent sections are clustered into themes aimed at realising the objectives of the survey.

\footnotetext{
${ }^{13}$ Ademefun Deji National Programme Manager (JONAPWD) Daily Trust Newspaper (2017) 'Nigeria: Three million children with disability out of school' available at https://allafrica.com/stories/201607140976.html (accessed February 13 2019).

${ }^{14} \mathrm{~N}$ Denzin The research act in sociology (1970) 186; NG Fielding \& JL Feilding Linking data (1986) 35.
} 
The first set of questionnaire is for children with disabilities in the sampled special schools. Considering the age and level of the learners, the classroom teachers, as well as sign language and braille interpreters assisted in carefully reading, explaining, signing and interpreting to the learners, in order to ensure easy assimilation and understanding of the contents of the questionnaire. The questions were explained one after the other, at the learners' pace. The questionnaire is rated on a four point scale of Strongly agree (4) Agree (3) Strongly disagree (2) and Disagree (1). The questions assisted in getting responses regarding the sufficiency of approaches adopted in the education of children with disabilities in special schools in Imo state. The higher the score, the higher the lack of sufficiency in the approaches adopted in the education of the learners.

The second set of questionnaire is for special school teachers. Questionnaire Items were based on participants' knowledge regarding major prerequisites underpinning the achievement of inclusive education for children with disabilities and the sufficiency of approaches adopted in the education of children with disabilities. The questionnaire is rated on a four point scale of Strongly agree (4) Agree (3) Strongly disagree (2) and Disagree (1), the higher the score, the higher the lack of knowledge of respondents and inadequacy of approaches adopted while teaching. Some special school teachers were also selected for further interviews and clarifications.

The third set of questionnaire targets officials of the Ministries of Education (States Universal Basic Education BoardSUBEB) within the selected state. Questionnaire Items were based on participants' knowledge regarding values underpinning the achievement of inclusive education for children with disabilities and the availability of accommodations in the classrooms. The questionnaire is rated on a four point scale of Strongly agree (4) Agree (3) Strongly disagree (2) and Disagree (1), the higher the score, the higher the lack of knowledge of respondents and absence of needed accommodations. In the end, strongly agree and agree is interpreted as yes, while strongly disagree is interpreted as no.

With regard to focus group discussions, there were also questions that guided focus group discussions. The focus group is comprised mainly of officials of the Nigeria Ministry of Education, education secretaries and special education unit staff of the Imo State Primary Education Board, special education teachers, children with disabilities and their parents, special school head teachers, special education teacher educators and professionals having different forms of disabilities.

\section{VALIDITY AND RELIABILITY OF INSTRUMENT}

Administration and retrieval of questionnaires was conducted within two weeks. In each school, questionnaire was administered and collected on the spot so as not to give room for external influences, loss of questionnaire and to keep reliability and accuracy at a satisfactory level. In the process of gathering data, the study also engaged in participatory observation of participants, sought clarifications where there are inconsistencies and made notes that were later transformed into related themes and categories.

\section{DATA ANALYSIS/INTERPRETATION}

Conceptually, the study uses the social model of disability perspectives based on the necessity to highlight the idea of inclusive equality as an end of law, policy or practice. This is with regard to the lived experience of a historically marginalised group, which in this sense refers to access to inclusive education in basic education of children with disabilities in special schools in Imo state. Here, the study seeks to align itself with the orientation of other theorists who perceive law, policy and practice as socially constituted. The social model of disability is a transformative method which conceives disability as the result of the approach in which the existing socio-economic situation interconnects with the human body. ${ }^{15}$ This is made obvious by looking at written texts and the social order which radiate arrangements that have the tendency to ignore a group's disadvantaged position. Social model theorists extol the idea of 'universal objective good' and seek to bring about 'normative transformation' for any hitherto marginalised group.

Using the social model of disability as an interpretive tool assists in exploring the link between the learning experiences of children with disabilities, inclusivity and the wider socio political and cultural context. However, the use of the social model of disability does not preclude the use of other perspectives that could assist in elucidating arguments in the study.

\section{ETHICAL CONSIDERATIONS}

In order to guarantee protection of the privacy and identity of the participants in this survey, rapport was established in the appropriate quarters and the permission of heads of schools, chief executives of establishments/institutions sought. In a similar manner, the purpose of the study was also explained to the participants. It was also explained to participants that they are at liberty to withdraw from participating in the discussions at any time they deem fit. This is to ensure that the consent of research participants was secured.

\section{DATA BACKGROUND: CLARIFICATION}

In a bid to explain the data used for analysis, presenting the size of questionnaire distributed as well as respondents' background is relevant. Tables 1, 2 and 3 clarify data used for the study.

\footnotetext{
15 CG Ngwena 'Deconstructing the Definition of 'Disability' under the Employment Equity Act: Social Deconstruction' (2006) 22 South African Journal on Human Rights 622;C Baylies 'Disability and the Notion of Human Development: Questions of Rights and Capabilities' (2002) 17 Disability and Society 725 at 727 and endnote 1 at 737; JE Bickenbach Physical Disability and Social Policy (1993) 21; M Jones \& LA Basser Marks 'Law and Social Construction of Disability' in Jones and Basser Marks (eds) ibid 3-34;
} 
Table 1: Total number of respondents sampled

\begin{tabular}{|c|c|c|}
\hline Respondents & Number & (\%)approx \\
\hline Teachers & 42 & 12 \\
\hline Learners & 312 & 88 \\
\hline $\begin{array}{c}\text { Sub-total of teachers } \\
\text { and learners used for the study }\end{array}$ & 354 & 100 \\
\hline IMSUBEB Officials & 26 & \\
\hline Grand total sampled for the study & 380 & \\
\hline
\end{tabular}

Table 2: Questionnaire Distribution

\begin{tabular}{|c|c|c|}
\hline Item & N & (\%)approx \\
\hline $\begin{array}{c}\text { No. of questionnaire properly filled and } \\
\text { returned }\end{array}$ & 376 & 99 \\
\hline $\begin{array}{c}\text { No. of questionnaire not properly filled and } \\
\text { returned }\end{array}$ & 4 & 1 \\
\hline \begin{tabular}{c} 
No. of questionnaire distributed \\
\hline
\end{tabular} & 380 & 100 \\
\hline
\end{tabular}

Table 3: Total number of properly filled responses used in the study

\begin{tabular}{|c|c|c|}
\hline Respondents & Number & (\%)approx \\
\hline Teachers & 42 & 12 \\
\hline Learners & 308 & 88 \\
\hline $\begin{array}{c}\text { Sub-total of teachers } \\
\text { and learners used for the study }\end{array}$ & 350 & 100 \\
\hline SUBEB Officials & 26 & \\
\hline Total properly filled and returned & 376 & \\
\hline
\end{tabular}

Additionally, 16 discussants participated in the focus group on planned dates. The sample is considered large enough for the study.

\section{PRESENTATION OF FINDINGS}

\subsection{Responses of participants}

In order to determine research participants idea about main prerequisites of inclusive education under normative law and the sufficiency of approaches adopted in the education of children with disabilities in Imo state special schools, the research used qualitative content analysis. ${ }^{16}$ This involved analysing each unit of data for purposes of clustering and identification of common themes.

\subsubsection{Background Information: Characteristics of respondents}

\section{Age of respondents}

The questionnaires reveal that the age of the learners fall within 8-15 years, aside the learners, the other respondents identified as adults:

Table 4

\begin{tabular}{|c|c|c|}
\hline Respondents & Number & (\%)approx \\
\hline Adults & 68 & 18 \\
\hline Learners (ranging from $8-15$ years) & 308 & 82 \\
\hline Total & 376 & 100 \\
\hline
\end{tabular}

\subsubsection{Qualification of Teachers}

Table 5

\begin{tabular}{|c|c|c|}
\hline $\begin{array}{c}\text { Qualification of special school teachers } \\
\text { in sampled schools }\end{array}$ & Number & (\%)approx \\
\hline FSLC/ SSCE & - & 0 \\
\hline NCE & 29 & 69 \\
\hline B.Ed & 10 & 24 \\
\hline Master & 3 & 7 \\
\hline Total & 42 & 100 \\
\hline
\end{tabular}

Features from table 5 indicate that 69 per cent of special school teachers hold National Certificate of Education, 24 per cent hold Bachelors degree, while 7 per cent hold Masters Degree in special education. It is also shown that less than 10 per cent of the special school teachers do not have higher degrees or further training in special education.

The educational levels of respondents from the State Universal Basic Education Boards range from Bachelor of Education, Bachelor of Arts /Bachelor of Science with a Post Graduate Diploma in Education, Masters Degree and Doctoral Degree. The former and present Chairpersons of the Imo State Universal Basic Education Boards often hold higher degrees, but they are usually political office holders, appointed by the state governors. They are typically not educators.

\subsubsection{Teachers'years of experience}

Table 6

\begin{tabular}{|c|c|c|}
\hline Teachers' Years of Experience & $\begin{array}{c}\text { Number in } \\
\text { Special School }\end{array}$ & (\%)approx \\
\hline $1-5$ & 10 & 24 \\
\hline $6-10$ & 9 & 21 \\
\hline $11-15$ & 14 & 33 \\
\hline$>=16$ & 9 & 22 \\
\hline Total & 42 & 100 \\
\hline
\end{tabular}

Years of experience of respondents from Imo State Universal Basic Education Board fall within 3 years and above. In respect of focus group discussion, aspects that were considered relevant and important regarding respondents personality mainly had to do with the experience and background of the participants in relation to disability issues and inclusive education practices in special education.

\subsection{Children with disabilities}

\subsubsection{Personal data/characteristics}

Children with disabilities that formed part of the sample size fall within 10 - 15 years and they were mainly children with sensory and intellectual disabilities. The learners were selected from basic 4 to junior secondary 3. Almost all the learners indicated that they did not attend early child learning and language development classes. Early child learning is

${ }^{16}$ E Henning et al Finding your way in qualitative research (2004) 104. 
considered an important aspect of inclusive education under the CRPD. ${ }^{17}$

\subsubsection{Provision of needed facilities in the school (accommodations)}

In all the schools visited, the learners responded that they were in special schools when asked to state the kind of school they attended. 72 per cent affirmed willingness to attend the same school with other children without disabilities provided necessary accommodations are made available. ${ }^{18}$ In all the special schools visited, the learners stated that they do not have the necessary support and facilities they require. About 28 per cent of the learners indicated that they would not want to be in the same class with children without disabilities in regular schools as a result of stigmatisation and fear of negative attitudes by learners as well as teachers. In the special school for the deaf, most of the learners highlighted that teachers use oral communication, gestures common with spoken English, American Sign Language and written words to teach and for assessments too. They also stated that they do not have audio-visual learning materials which help learners to understand new knowledge that can be practically explained.

All learners with visual impairments and some deaf learners who use wheelchair also indicated that moving around the school is often difficult due to accessibility problems, including narrow doorways and steep steps. They also indicated that lessons are not brief and are usually complicated because teachers do not repeat instructions, rather they paraphrase. The responses recorded further indicate that the learners really struggle to read and understand written texts especially when guidance is not provided. Majority of the learners also responded that learning is not paced to enable them find information in textbooks or tape lectures. Diagrams and charts are also not provided in tactile form. The learners also indicated that they are not usually given the opportunity to specify the preferred format of instruction. In the end, the learners pointed out that they enjoy going to school because they wanted to learn. They also exhibited concern on the nonaccommodation of their individual learning needs.

\subsubsection{Education and assessment activities}

Most of the learners in the schools visited responded that teaching and assessments are not responsive to their individual needs and abilities. It was also observed that some learners with severe disabilities in some of the schools could do better with functional skills (informal education) instead of reading and writing. 88 per cent of the learners indicated that

\footnotetext{
17 CRPD art. 24(2)(c).

${ }^{18}$ This idea of the learners aligns with UNESCO statement which recognises that regular schools with inclusive orientation are the most effective means of combating discriminatory attitudes, creating welcoming communities, building inclusive society and achieving education for all. More so, they provide an effective education to the majority of children and improve the efficiency and ultimately the cost-effectiveness of the entire education system. UNESCO, 1994, 10.
}

assignments and examinations are given using only written texts and no visual formats. Almost all learners with visual impairments highlighted that they require a reader, scribe, closed circuit television, better lighting, separate room with proctor or computer to read or produce answers. They also require exams and assignments to be given in alternative formats, e.g Braille, modified layout, large prints.

During focus group discussions, deaf learners and visually deaf learners that were present identified the absence of audiovisuals that complement oral, sign or written language as a major barrier to their learning. Flexible modification of the curriculum content, approaches and strategies with a common vision to cover all learners was also highlighted by participants. The learners also exhibited concern about the use of written exams as the only means of evaluation used by their teachers to evaluate them. They hinted that this approach affects their active involvement and development of potentials. Special education professionals particularly emphasised the need for the education system to incorporate in the curriculum, vocational and creative arts periods that can awaken learners' interests. The need for teachers to dedicate more time to teaching the learners in the language of the immediate environment of the learner was also highlighted. The use of written texts and examinations as the only means of assessment and evaluation was criticised by the focus group discussants who described such an approach as limiting.

The head teachers and teachers in the focus group prioritised parental involvement in the education of children with disabilities in order to enhance the process of learning. Indeed, most parents are unaware of the importance of early identification and intervention supports, therapeutic services, and early childhood education. Consequently, parents need to attend parent-teachers meeting and school open days to discuss each child's individual education programme and progress in school and how to assist with the child's assignments. Parents in turn need to be supported in other to play a full part in helping the child.

\subsection{Special school teachers}

In the special schools visited, majority of the teachers expressed limited knowledge and doubts concerning the practice of inclusive education in special schools. Very few teachers stated that inclusive education is achievable for children with disabilities in special schools, provided needed accommodations are prioritised.

\subsubsection{Consciousness regarding actualising inclusive education policy in special education}

Table: 7: Response on actualising policy on inclusive education in special education

\begin{tabular}{|c|c|c|}
\hline $\begin{array}{c}\text { Consciousness of the actualizing inclusive } \\
\text { education in special education }\end{array}$ & Numbers & (\%)approx \\
\hline No & 33 & 79 \\
\hline Yes & 9 & 21 \\
\hline Total & 42 & 100 \\
\hline
\end{tabular}


Majority of the teachers pointed out that they are familiar with the principle on inclusive education which requires that learners with disabilities need to be included in 'regular schools' in age appropriate general education classes. Close to 70 per cent emphasised that this understanding cannot be extended to already existing special schools. However, it is significant that about 26 per cent understood inclusive education means transforming how schools presently function. Indeed, inclusive education has particular implications for special education. Inclusive education is not achieved simply by admitting children with disabilities in regular education classes. Rather, teachers, schools, and the general education system need to transform in order to accommodate the diversity of learners.

\subsection{2 \\ Teachers seminars/workshops/sponsorship}

Table: 8: Teachers' response concerning participation in seminars/workshops

\begin{tabular}{|c|c|c|}
\hline $\begin{array}{c}\text { Participation in any inclusive } \\
\text { education seminar/workshop }\end{array}$ & Number & (\%)approx \\
\hline Yes & 10 & 24 \\
\hline No & 32 & 76 \\
\hline Total & 42 & 100 \\
\hline
\end{tabular}

As seen in Table 8, state level capacity to resource and implement participation of special school teachers in inclusive education seminars/workshops is not encouraging and thus requires ongoing support.

Table 9: Teachers' reaction regarding workshop funding

\begin{tabular}{|c|c|c|}
\hline Seminar/Workshop participants & $\mathrm{N}$ & (\%)approx \\
\hline Not government sponsored & 39 & 93 \\
\hline Government sponsored & 3 & 7 \\
\hline Total & 42 & 100 \\
\hline
\end{tabular}

Table 9 above; indicate that the government does not sponsor most special school teachers for seminars and workshops on inclusive education in order to provide teachers the opportunity to learn and exchange ideas on the meaning and challenges of inclusive education. 95 per cent of the teachers specified that they are unprepared with respect to their responsibilities regarding the implementation of inclusive education in special education.

Head teachers of the special schools sampled emphasised the need to offer training and orientation to teachers, IMSUBEB officials and politicians so as to increase their understanding and practical progress on inclusive education. One of the head teachers highlighted that fostering linkages between IMSUBEB and disability experts in Nigeria will help to provide greater access to normative good practices in teaching children with disabilities. Most responses point toward the fact that teachers are willing to attend seminars and workshop on inclusive education, but that the state fails to approve funding in that regard. It was highlighted that during such trainings and workshop, only one teacher from each special school often gets funding to attend.
Special school teachers and learners who participated in the focus group discussions reiterated lack of sufficient knowledge on inclusive education practices and lack of instructional materials for teaching children with disabilities. The focus group participants further validated that a greater percentage of the teachers found in special schools for the deaf or in 'inclusive schools' do not have a professional qualification or skill in special or inclusive education. They attributed this to lack of understanding. The failure of government to provide some form of incentive for special education teachers was also implicated.

\subsubsection{Educational approaches}

On teaching approaches and strategies, 70 per cent of the teachers indicated they use more than one method to demonstrate or explain lessons and instructions. However, nearly 87 per cent, reiterated that they lack sufficient knowledge on inclusive education practices, lack instructional materials for teaching children with disabilities, lack cooperation from fellow teachers and school administrators and lack proper incentives for accommodating the challenges of inclusive education. About 95 per cent of the teachers found in the special schools sampled stated that they lower standards in the curriculum in order to make learning easier for children with disabilities. Thus these teachers seem more interested in achieving outcome rather than equal opportunity in education that would enable learners to demonstrate what they have learnt.

On the use of ICT tools to support all learners, almost all the teachers responded by agreeing that they do not have access to ICT tools that support learners. All the teachers interviewed indicated that they do not share ideas with parents to help with homework. 86 per cent do not break students into smaller groups or break assignments into smaller pieces to work on in short time periods. There is no evidence of ongoing assessment or monitoring linked with teaching, hence teaching approaches do not give room for prescriptive and flexible delivery of lessons. It is also in evidence that reading is not linked to spelling as well as writing and most teachers do not engage in repetitive and cumulative teaching approaches for children with specific learning difficulties other than sensory or visual impairments.

In the special schools for the deaf, some teachers responded that they give instructions, assignments and examinations using total communication, ${ }^{19}$ whereas few of them indicated

\footnotetext{
${ }^{19}$ Total Communication invariably uses every means of communication like speech, sign language, lip-reading, writing, gesture, visuals. It also accommodates the use of residual hearing through amplifications like hearing aids, cochlea implants. While total communication uses signs, the signs used are believed to be spoken English language followed by simultaneous American language signs. See PA Ajavon 'An overview of deaf education in Nigeria' http://www.deafchildworlwide.info/document.rm?id=2875 (accessed 11 February 2020). Ahough this approach can encourage general communication between teachers and deaf learners and may improve the assimilating process, it has been observed that learners who follow this approach solely, experience difficulties with their language skills especially in relation to reading, writing and the reception of knowledge due to lack of
} 
they deliver lessons by means of spoken English language and American Sign Language. Majority said they use only American Sign Language, even as very few of the teachers highlighted that they combine spoken and written English language with American Sign Language.

Teachers of the vision impaired learners were found teaching without verbal description of the visual aids or writings on the whiteboards, or spelling aloud difficult words or names. On the question whether talking through calculations and procedures as they are carried out is a necessary strategy for teaching learners with vision impairment, some of the teachers responded using strongly agree, while many of the teachers responded with strongly disagree and disagree. It was also gathered that diagrams and chart are not usually presented in tactile form and learners are not encouraged to take turns to speak or introduce themselves during class discussions. Working with students in order to find out strategies and adjustments that will help them to participate fully is considered necessary for inclusion.

Through participatory observation, it was noticed that some learners with intellectual disabilities as well as autism were in the same class with deaf learners and teachers lacked the resource and skills to teach these categories of learners. Children with autism as well as children with intellectual disabilities were been taught like deaf learners without recourse to their individual learning needs. During focus group discussions, it was learned that teaching autistic learners require gentle but firm teachers, play activities and might involve a speech therapist. It was further gathered that most autistic persons think in pictures as first language rather than spoken language which is considered a second language. Getting the best out of autistic learners means avoiding long strings of verbal learning instructions. It was also confirmed that many children with autism have worst handwriting but are good at art, drawing and computer programming. It is considered that emphasis should be on developing these talent areas and skills for full participation in the society. Children with autism need to be protected from noise as it can trigger bad behaviour. However, sound sensitivity to a particular sound can be desensitised using a tape recorder which allows the child to set off the sound and gradually amplify its volume.

Likewise, a child with intellectual disabilities can do well in school with individualised help from teachers and associated services. Usually, the measure of support that is contemplated depends upon the level of intellectual disability. Associated services may involve instruction personnel, equipment or other facilities that will enable children with intellectual disabilities to be educated among their peers to the maximum extent appropriate. Children with intellectual disabilities need

exposure to language development using the language of the immediate environment. See E Smuts 'Schools-Deciding on a school for the deaf' in Hugo \& Blumberg (eds) Challenges and choices (2002) 54; RE Johnson et al Unlocking the curriculum: Principles for achieving access in deaf education' (1989) 89-3 Gallaudet Research Institute Working Paper 5. assistance with adaptive skills (communicating with others, taking care of personal needs, social skills, reading, writing and basic math and skills that will help them as they grow older) as highlighted by participants during focus group discussions.

Participants in the focus group went further to state that children with intellectual disabilities learn better with additional support and modifications in the classroom, and in the type of activities they do. Some of the modifications mentioned include (i) calm work space that allows for focus on tasks. (ii) functional activities that are practical and valuable (iii) replication of concepts many times to help them remember and retain information (iv) teacher-student ratio which ideally should be 1 teacher to 3 children with disabilities (v) using all senses to learn (vi) ensuring that safety measures are in place (vii) making schedules that have short activity times and alternate between physical and sitting down activities.

Unfortunately, in the sampled schools these provisions were not seen to be in place as some of the teachers indicated that inclusion of children with autism and children with intellectual disabilities in their classroom increase their work load. While it is important that children with autism make progress within the general education curriculum, (that is the same curriculum used by deaf learners and other children without disabilities) it is also crucial that support is provided in the classroom using appropriate skills and accommodations that speak to the need of each learner. Simply keeping autistic children in the same classroom with deaf learners where they are expected to adapt to the classroom based on their ability without structural changes is considered discriminatory and subtractive.

On student-teacher ratio, it has been observed that the number of learners outnumber the teacher(s) per class in some of the special schools sampled within Owerri Zone. The number of learners in a particular classroom is in the ratio of 1: 35 indicating that there are 35 students for every one teacher. This is against the stipulated teacher/pupil ratio of 1:10 under the Nigerian National Policy on Education, ${ }^{20}$ or even the 1 teacher to 3 children with disabilities as suggested by special education professionals during focus group discussions. Moreover, several of school administrators and teachers lack the professional skills to work effectively with varied disabilities. The implication is that each classroom will require different skilled teachers in each inclusive classroom. Such a situation will enhance academic performance and will make it possible for teachers to easily identify the unique needs of each learner.

9.3.4 Government directives regarding the adoption of inclusive approaches in special schools

\footnotetext{
${ }^{20}$ Nigeria National Policy on Education, sec 7, para 123(c).
} 
Table 10: Responses on directives from government regarding the use of inclusive education

\begin{tabular}{|c|c|c|}
\hline $\begin{array}{c}\text { Any directive from government on } \\
\text { inclusive education for special school } \\
\text { learners }\end{array}$ & Number & (\%)approx \\
\hline Agreed & 4 & 10 \\
\hline Disagreed & 38 & 90 \\
\hline & 42 & 100 \\
\hline
\end{tabular}

Table 10 indicates the absence of official directive and guide on the need to adopt inclusive education approaches and principles in special schools. Most head teachers in the schools visited reported that they talk to teachers about improvements synonymous with inclusive education approach based on directives from officials of IMSUBEB, but none of the teachers reported interacting with the IMSUBEB officials or professionals in inclusive education directly. This means that Imo state has no precise government mandate to ensure provision of inclusive education for learners in special schools. The divided opinion on directive/mandate significantly suggests that the level of sensitisation and commitment towards realising inclusive education in special schools is very low.

Regarding monitoring and supervision, some of the teachers specified that officials from IMSUBEB usually come twice a term. They however, stated that the usual pattern of visits involve chatting with the head teacher, reviewing submitted lesson plans, discussing challenges that involve conditions of classroom and no discourse on how to advance the academic needs of children with disabilities through inclusive education.

\subsubsection{Curriculum content}

Table 11: Response regarding curriculum content for special school learners

\begin{tabular}{|c|c|c|}
\hline Responses on Curriculum content & Number & (\%)approx \\
\hline Agreed on content being same & 19 & 45 \\
\hline Disagreed on content being same & 14 & 33 \\
\hline No response & 09 & 22 \\
\hline Total & 42 & 100 \\
\hline
\end{tabular}

With regard to curriculum for special education learning, teachers opinion differed in the various schools visited as seen in table 11 . Practically 46 per cent of the teachers responded that the curriculum of special school learners is same with learners without disabilities in the regular schools. About 25 per cent could not respond, while 29 per cent responded that special school learners do not have the same curricula with regular school learners.

It is important to note that the Nigeria national policy on education provides a common curriculum for all primary school learners in Nigeria, including special schools, ${ }^{21}$ as well as post-primary students ${ }^{22}$ however, the document did not to

\footnotetext{
${ }^{21}$ Nigeria National Policy on Education, $2004 \sec 2$ para 26.1.

${ }^{22}$ National Council for Curriculum Assessment, 1999.
}

provide a clear directive that will satisfy the diverse needs of learners. This means that educational administrators must consciously plan and come up with diversified programme that will accommodate the different needs of which inclusive education in special education is one of such programme. ${ }^{23}$ This invariably implies that educational administrators must enlighten and sensitise teachers on a broad variety and array of different teaching patterns.

Even though school administrators do not require being disability rights experts, they need basic skills and knowledge that will assist the improvement and realisation of inclusive education for all. Special education being synonymous with education of people who need additional, academic and collective assistance, ${ }^{24}$ adaptation of the usual school curriculum and special education practices is imperative to enable learners develop and participate fully in the society.

In support of the above, discussants at the focus group stated that an appropriate curriculum is usually planned in a manner that would provide equal opportunities, activities and experiences for the education of children with disabilities. Focus as gathered should be on activity based learning, interaction with immediate environment, self-directed learning, development of key skills within the general education curriculum, the use of variety of assessment tools, the use multi-disciplinary approaches while teaching, cooperative and group work as well as peer learning. ${ }^{25}$ The areas in which curriculum planners and teachers should be commissioned to identify as stated include; the content of the curriculum that is taught to children within the general education system, an adopted curriculum that speak to the peculiar needs of children with special needs in terms of breadth, flexibility and the choice it offers in the selection and sequencing of content; curriculum that is particularly designed to attend to the learning needs of children, and also make the education of children with disabilities valuable. ${ }^{26}$

With regard to teaching methodologies in curriculum planning, special education professionals highlighted the imperatives of individualisation of lessons, deemphasising structure and encouraging self-selected activities, motivating learners and deep teacher support, using audio-visuals, using concrete instead of abstract materials, deemphasising competition, emphasising group work, bringing a learner in a

\footnotetext{
${ }^{23}$ IN Mogbo 'Restructuring the curriculum of the disabled for selfsustenance: Counseling implications' (2002) 6 Journal of National Council for Exceptional Children 76

${ }^{24}$ ED Ozoji Re-positioning special needs education for effective service delivery in Nigeria' (2005) 8 Deka Special Education Monograph series

${ }^{25}$ Here, reference was made to AI Oboegbulem 'Administrative strategies for the preparation of teachers of special needs children : The exceptional child' 7 Journal of the National Council for Exceptional Children 319.

${ }^{26}$ See RC Nwachukwu 'Curriculum planning for special needs children: Contemporary issues in special needs education' (2006) 7 Journal of the National Council for Exceptional Children 276 as cited by the focus participants.
} 
strategic sitting position in the classroom when necessary and opting for special remedial programme when needed.

\subsection{IMSUBEB (Imo State Universal Basic Education Board) - officials that manage basic education in the state}

This section looks at the views and opinions of Imo State Universal Basic Education Board officials, including selected staff of the special education unit/department, education secretaries and other relevant officials. These officials are charged with the responsibility of the management of basic education, involving management of Early Child Care Development (ECCD), Basic 1-6 and Junior Secondary Schools owned by the government. Their responses are found below.

\subsubsection{Perception concerning actualising inclusive education policy in special education}

About 78 per cent of the IMSUBEB officials exhibited consciousness regarding actualisation of inclusive education for children with disabilities in special schools as stipulated in the Nigeria National Policy on Education (2004), National Policy on Special Needs Education (NPSNE) and its Implementation guidelines (2015) as well as the National Policy on Inclusive Education in Nigeria (NPIEN) 2016. They however, stated that accommodations in schools are usually made based on budgetary considerations more willingly than on an assessment of the actual needs of learners with disabilities in special schools.

Pushing it further, 95 per cent of the officials mentioned that coordinating services and providing individual support to children with disabilities require resources and inadequate funding get in the way of professional development towards actualising inclusive education in special schools. Cases where available funds that would have assisted in realising inclusive education in special schools are not accessible by special school administrators were highlighted as having contributed to the neglect in the area of needs assessment, infrastructure, and equipment and learning materials. Hence policies on inclusive education remain unimplemented and access to inclusive education is limited for children with disabilities in special schools. Findings further reveal that special education professionals are not heading special education units and this invariably stultifies the implementation and administration of inclusive education in special needs education.

It is pertinent to state here that the remaining percentage of the officials however, feigned ignorance in their responses regarding actualising inclusive education policy in special education. Their responses indicated irregularities with regard to the normative principles underlying inclusivity in education. What this implies is that committed efforts are not directed at engaging all IMSUBEB officials as stakeholders in education on proper engagement with inclusive approaches in education so as to equip them with the needed leadership for monitoring implementation. Essential knowledge and skill in inclusive education is required for fundamental special education leadership tasks.

9.4.2 Awareness of the existence of laws and policies on inclusive education for learners, with disabilities

Regarding, policy awareness, 47 per cent of the interviewed officials indicated knowledge of the existence of a national policy on inclusive education for learners with disabilities. Some also acknowledged the existence of Imo state policy on inclusive education, although the document was not made available. While more than 50 per cent expressed poor knowledge of the existence of the national policy.

\subsubsection{Efforts at realising inclusive education for learners with disabilities}

Responses of interviewed officials regarding the Boards efforts towards realising inclusive education for learners with disabilities were consistent. All highlighted the progressive provision of infrastructural support. None of the officials seemed to appreciate the necessity for learners to participate in the general education curriculum, sign language training for teachers, Braille training, curriculum adaptation training, identification of learners needs and the provision of appropriate guidelines as well as modification of assessment styles in line with individual needs.

\subsubsection{Existence of diagnostic centres for early assessment of learning disability}

The officials about 45 percent, stated that assessment is usually done by the head teachers/support staff based on personal observation. Almost 40 per cent highlighted that assessment is done by parents. While only 14 per cent linked assessment to medical report. In summary, the study found that there is no specialised diagnostic centre for the purpose of assessing learners with disabilities.

\section{CONCLUSION}

Looking back on the findings that have been set out in this study, there is an understanding that there has been a trajectory of little progress in advancing access to inclusive education practice in special education in Imo State. Consequently, the inclusion of learners with disabilities in special schools requires a systemic change. Since Nigeria has ratified the CRPD and its optional protocol as well as domesticated same, there is need to emphasise its implementation at the state level with special attention to article 24 on inclusive education. In doing so, states must be encouraged with resources, awareness on the need to realise inclusive education for learners with disabilities must be created, curriculum and teachers trainings to meet learners' needs must be developed, and universal design learning which involves structural and infrastructural changes must be taken up. Furthermore, parents must be informed on the need to participate and support teachers so as to enhance the full accommodation of learners with disabilities in schools and in the society. 